\title{
Ruptura De Bexiga Após Trauma Abdominal Leve: Relato De Caso
}

\author{
Bladder Rupture After Minor Abdominal Trauma: Case Report
}

Vinícius André Santos Mattos ${ }^{\dagger *}$, Aline Trovão Queiroz $z^{\ddagger}$ Eduardo Tavares Lima Trajano ${ }^{\ddagger}$, Márcio Terra Passos ${ }^{\ddagger}$

Como citar esse artigo. Mattos, V.A.S.;

Queiroz, A.T., Trajano, E.T.L.; Passos, M.T. P. Ruptura de bexiga após Trauma Abdominal Leve: Relato de casos. Revista de Saúde. 2018 Jul./Dez.; 09 (2): 49-51.

\section{Resumo}

A ruptura da bexiga pode ocorrer decorrente de trauma direto (ruptura intraperitoneal), ou por fragmentos de ossos pélvicos decorrentes de fratura (ruptura extraperitoneal). A bexiga vazia apenas será lesada se houver um esmagamento ou ferimento penetrante, já que nessa condição ela fica protegida pelos ossos pélvicos. O método de imagem padrão ouro para o diagnóstico é a cistografia, entretanto ela vem sendo substituída pela cistotomografia devido à capacidade desta de melhor avaliar lesões associadas. A conduta terapêutica na ruptura intraperitoneal de bexiga é a cirurgia, por meio do desbridamento das áreas desvitalizadas, rafia e lavagem da cavidade abdominal com solução salina a 0,9\%. O objetivo do artigo foi relatar um caso de ruptura de bexiga intraperitoneal em um paciente hígido após um trauma abdominal leve. Os casos já relatados posteriormente a um trauma abdominal leve ocorreram, principalmente, em pacientes que já possuíam certa fragilidade da parede vesical, etilistas crônicos ou portadores de retenção urinária. Conclui-se que, independente da intensidade do trauma é importante considerar a ruptura da bexiga e uma rápida abordagem cirúrgica, evitando complicações de um diagnóstico prorrogado.

Palavras-chave: Ruptura intraperitoneal de bexiga; Trauma abdominal leve.

\begin{abstract}
Bladder rupture may occur due to direct trauma (intraperitoneal rupture), or fragments of pelvic bones from fracture (extraperitoneal rupture). The empty bladder will only be injured if there is a crushing or penetrating injury, as in this condition it is protected by the pelvic bones. The gold standard imaging method for diagnosis is cystography, however it has been replaced by cystotomography due to its ability to better evaluate associated lesions. The therapeutic approach in intraperitoneal bladder rupture is surgery by debridement of the devitalized areas, raffia and lavage of the abdominal cavity with $0.9 \%$ saline solution. The aim of the paper is to report a case of intraperitoneal bladder rupture in a healthy patient after mild abdominal trauma. The cases already reported after mild abdominal trauma occurred mainly in patients who already had some fragility of the bladder wall, chronic alcoholics or patients with urinary retention. It is concluded that, regardless the intensity of the trauma, it is important to consider bladder rupture and a rapid surgical intervention, avoiding complications of a delayed diagnosis.
\end{abstract}

Keywords: Intraperitoneal bladder rupture; Mild abdominal trauma.

\section{Introdução}

A ruptura de bexiga após um trauma abdominal externo ocorre normalmente quando o órgão está distendido ou por fratura de ossos pélvicos ${ }^{1}$. Quando a bexiga está vazia, ela fica protegida pelos ossos da pelve, entretanto quando ela se distende e se move em sentido do abdome ou após fratura dos ossos pélvicos, a proteção que se tinha é perdida ${ }^{2}$.

A causa mais comum de trauma externo levando a ruptura de bexiga é por acidente de veículos quando o paciente está em uso de cinto de segurança e com a bexiga distendida ${ }^{3}$. De acordo com Kessler et. al. ${ }^{3}$, dos pacientes que tiveram lesões vesicais associadas ao trauma abdominal contuso, 90\% foram relacionadas com acidente de veículos usando o cinto de segurança.

Quando se tem uma pressão súbita contra a parede abdominal ou um trauma associado a uma desaceleração rápida, ocorre um choque dentro da bexiga, tanto pelo evento traumático em si, como também pela contração do músculo detrusor e trígono vesical ${ }^{4}$. Esse mecanismo vai levar a uma distensão da região póstero-superior que, por ser o local mais frágil do órgão, pode se romper. $\mathrm{O}$ mecanismo de ruptura vesical extraperitoneal, pode ser de forma direta quando espiculas do osso fraturado rompem a cúpula vesical, por uma tração violenta ou rompimento dos ligamentos ${ }^{4}$.

O objetivo do artigo foi relatar o caso de uma ruptura intraperitoneal de bexiga em um paciente

Afiliação dos autores:

† Discente do Curso de Graduação em Medicina da Universidade de Vassouras, Vassouras, Rio de Janeiro, Brasil. vinycius.andre@gmail.com

\$ Docente do Curso de Graduação em Medicina da Universidade de Vassouras, Vassouras, Rio de Janeiro, Brasil.

*Email de correpondência: vinycius.andre@gmail.com 
previamente hígido após sua filha pular em seu abdome.

\section{Relato de caso}

Paciente masculino, 26 anos, deu entrada na emergência do Hospital Universitário de Vassouras com relato de que há, aproximadamente, nove horas estava brincando com sua filha de seis anos quando a criança pulou sobre seu abdome. Evoluiu com dor súbita de forte intensidade, difusa por todo abdome e anúria. Informou estar poliúrico devido à ingestão de bebida alcóolica.

Ao exame o abdome do paciente apresentavase rígido, peristáltico, fortemente doloroso a palpação superficial e profunda sem sinais claros de irritação peritoneal. Sinais Vitais: Pressão arterial: 120/80 mmHg,
Frequência cardíaca: 95 bpm, Saturação de oxigênio: 98\%, Frequência respiratória: 19 irpm.

Realizado cateterismo vesical de demora apresentando drenagem de líquido hemorrágico. Solicitado tomografia computadorizada contrastada que evidenciou líquido livre na cavidade abdominal (Figura $1)$.

O paciente foi encaminhado para laparotomia exploratória que constatou ruptura de bexiga intraperitoneal de aproximadamente 5 centímetros, sendo realizado rafia da bexiga com fio absorvível categute cromado 00 , chuleio festonado e lavagem da cavidade abdominal com soro fisiológico aquecido (Figura 2).

O paciente obteve alta hospitalar com recuperação total da função vesical após quatro dias de internação.

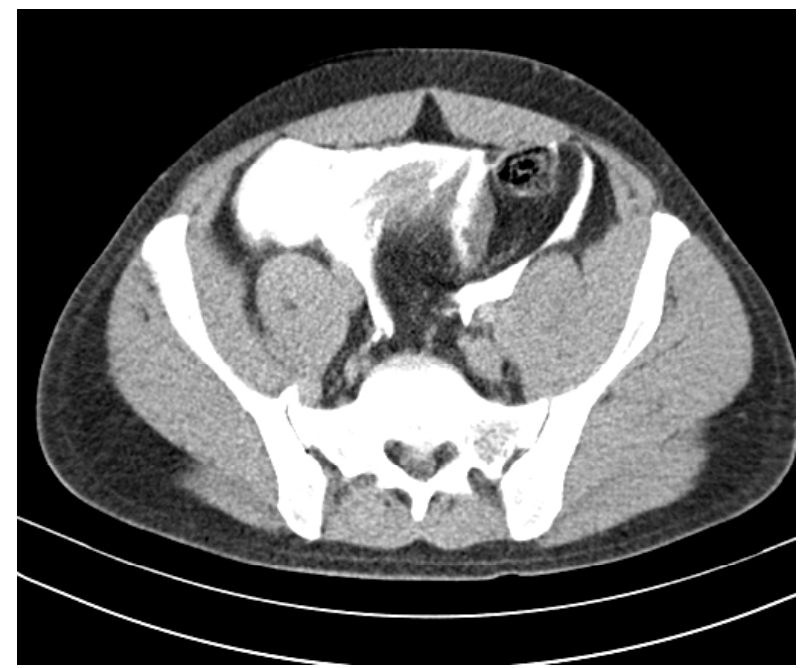

Figura 1. Tomografia computadorizada de abdome evidenciando contraste livre na cavidade abdominal

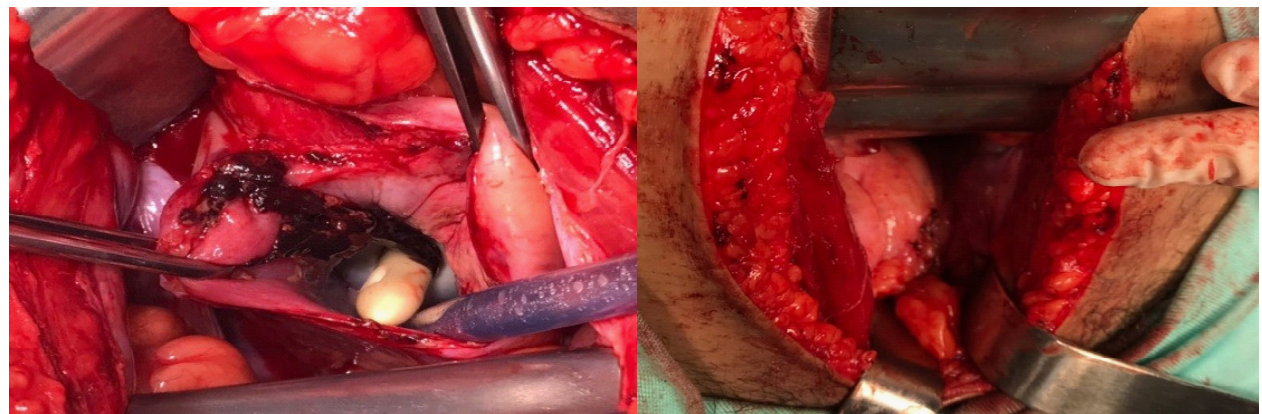

Figura 2. Bexiga antes (2 a) e após a rafia do órgão ( 2 b ) 


\section{Discussão}

As lesões que acometem o trato urinário inferior podem ser em consequência de um trauma fechado, penetrante ou iatrogênico ${ }^{5}$. A ruptura da bexiga ocorre quando a mesma está distendida e diante da compressão de sua superfície por um trauma, a cúpula vesical se rompe (ruptura intraperitoneal), ou então por ossos pélvicos quando estes sofrem alguma fratura (ruptura extraperitoneal) ${ }^{1}$.

A bexiga vazia apenas será lesada se houver um esmagamento ou ferimento penetrante já que nessa condição ela fica protegida pelos ossos pélvicos 5 . Quando está repleta de urina, há um crescimento do órgão para a cavidade abdominal, o que favorece para sua ruptura diante de um trauma sobre o abdome ${ }^{2}$.

A mortalidade dos pacientes que apresentam a ruptura intraperitoneal é menor quando comparada a extraperitoneal: a primeira de $12 \%$ enquanto a segunda há uma variação de 21 a 34\%, esse fato possivelmente está associado às outras injúrias que se tem na extraperitoneal ${ }^{4}$.

O método de imagem padrão ouro para o diagnóstico é a cistografia, onde se observará um vazamento do contraste, com especificidade de 85 a $100 \%{ }^{7}$. Entretanto, quando as alças intestinais são capazes de impedir que haja o extravasamento do líquido para a cavidade abdominal, ao tamponar o local da ruptura, o diagnóstico pode não ser conclusivo com esse método ${ }^{7}$.

Apesar da eficácia comprovada da cistografia, a cistotomografia vem substituindo este exame no diagnóstico de lesões vesicais em muitos casos. Isso ocorre pelo fato da tomografia permitir avaliar a presença de lesões de outros órgãos abdominais, como o próprio rim, além de possíveis fraturas pélvicas, o que encurta o tempo do diagnóstico e logo da abordagem terapêutica ${ }^{2}$.

O peritônio pélvico recobre a bexiga o que permite, em uma ruptura intraperitoneal, que a urina flua e permaneça no abdome. Se a mesma não estiver infectada, poderá não ter sintomas, caso contrário, terá uma peritonite, logo, um abdome agudo ${ }^{3}$.

Devido à presença da urina no peritônio abdominal haverá absorção de parte dela, podendo ocorrer desequilíbrios eletrolíticos, acidose, falsa insuficiência renal ou uremia ${ }^{3}$.

Os casos já relatos de ruptura intraperitoneal após um trauma abdominal leve ocorreram em pacientes que já possuíam certa fragilidade da parede vesical, etilistas crônicos ou portadores de retenção urinária ${ }^{3}$.

A conduta terapêutica na ruptura intraperitoneal de bexiga é a cirurgia, por meio do desbridamento operatório, realização da rafia no local da perfuração vesical e lavagem da cavidade abdominal com solução salina a $0,9 \%$ afim de retirar a urina livre no abdome. A laparoscopia é uma alternativa quando se tem dúvida do diagnóstico após a realização dos métodos de imagem ${ }^{6}$.

Como complicação do tratamento cirúrgico podese ter formação de abcessos, fístulas, ou divertículos urinários ${ }^{3}$.

\section{Conclusão}

Conclui-se que o trauma externo sobre o abdome levando a ruptura de bexiga está associado a impactos de alta intensidade, sendo os casos descritos mais comumente em acidentes de carro. O relato apresentado mostra a relevância de considerar, independente da intensidade do trauma, a ruptura da bexiga como consequência do evento e uma rápida abordagem cirúrgica. Dessa forma, complicações de um diagnóstico prorrogado poderão ser evitadas.

\section{Referências}

1. Cury J., Mesquita JLB de, Pontes J, Oliveira LCN de, Cordeiro M, Coelho RF. Trauma Urológico. Ver Med (São Paulo). 2008 jul.-set; 87 (3): 184-194.

2. Corrieri JN, Sandler CM Jr. Bladder rupture from external trauma diagnosis and management. World J Urol. 1999; 9: 84-89.

3. Kessler DO, MD, MSCI, Francis DL, Jenssen DE. Bladder Rupture After Minior Accidental Trauma. Pediatr Emer Care. 2010; 26: 34-35.

4. Festini G, Gregorutti S, Reina G, Bellis GB. Isolated Intraperitoneal Bladder Rupture in Patients With Alcohol Intoxication and Minior Abdominal Trauma. Annals of Emergency Medicine, 1991, 1371-1372.

5. Bigongiari RL, Amis SE Jr, Bluth EI, Bush WH Jr, Choyke PL, Fritzsche PJ, et al. Trauma de Bexiga e Uretra. Revista do Colégio Brasileiro de Radiologia. 2005. Edição 1; vol 1.

6. Gomes CA, Figueiredo AA de, Júnior CS, Netto JMB, Tassi FR. Abdome agudo: Ruptura espontânea de bexiga como um importante diagnóstico diferencial. Ver. Col. Bras. Jul/Agos 2009; vol 36.

7. McAninch JW, Lue TF. Urologia Geral de Smith e Tanagho. 18 edição Porto Alegre: AMGH, 2014. 